\title{
[ARTIGO RETRATADO] Diffusion Model Applied to Postfeeding Larval Dispersal in Blowflies (Diptera: Calliphoridae)
}

\author{
RC Bassanezi/ ${ }^{+}$; MBF Leite*; WAC Godoy**; CJ Von Zuben***; FJ Von Zuben****; SF \\ dos Reis*****/ ${ }^{+}{ }^{++}$
}

Departamento de Matemática Aplicada, IMECC, Universidade Estadual de Campinas, SP, Brasil *Instituto de Ciências Exatas, Pontifícia Universidade Católica de Campinas, SP, Brasil **Departamento de Parasitologia, Universidade Estadual Paulista, Botucatu, SP, Brasil ***Departamento de Zoologia, Universidade de Brasília, Brasília, DF, Brasil ****Departamento de Engenharia de Computação e Automação Industrial, Universidade Estadual de Campinas, SP, Brasil $* * * * *$ Departamento de Parasitologia, Universidade Estadual de Campinas, Caixa Postal 6109, 13083-970 Campinas, SP, Brasil

The article "Diffusion Model Applied to Postfeeding Larval Dispersal in Blowflies (Diptera: Calliphoridae)" published in Memorias do Instituto do Oswaldo Cruz 92(2):281-286, 1997, dx.doi.org/10.1590, authored by RC Bassanezi, MBF Leite, WAC Godoy, CJ Von Zuben, FJ Von Zuben, and SF dos Reis has been retracted. We have been informed about the use of graphical figure presentation published in Journal of Theoretical Biology vol. 185(4):523-531 1997, and following a careful analysis of the content in both papers, we concluded that the figure presented in Mem. Inst. Oswaldo Cruz 92(2):281-286, 1997 constitutes plagiarism. Consequently, we decided to retract this paper.

\section{Adeilton Alves Brandão,}

Editor de Publicação 


\title{
Diffusion Model Applied to Postfeeding Larval Dispersal in Blowflies (Diptera: Calliphoridae)
}

\author{
RC Bassanezi/ ${ }^{+}$, MBF Leite*, WAC Godoy**, CJ Von Zuben***, \\ FJ Von Zuben****, SF dos Reis*****/+/++
}

\begin{abstract}
Departamento de Matemática Aplicada, IMECC, Universidade Estadual de Campinas, SP, Brasil * nstituto re Ciências Exatas, Pontifícia Universidade Católica de Campinas, SP, Brasil **Departamento de Pa asitologi Universidade Estadual Paulista, Botucatu, SP, Brasil *** Departamento de Zoologia, Universidade c Bras" a, Brasília, DF, Brasil ****Departamento de Engenharia de Computação e Automação Indu nal, $\mathrm{Q}$ versıdade Estadual de Campinas, SP, Brasil *****:Departamento de Parasitologia, Universidade E dual de $($ impinas, Caixa Postal 6109, 13083-970 Campinas, SP, Brasil
\end{abstract}

This paper presents a diffusion model of larval dispersal especifically des nea account for particular aspects of postfeeding larval dispersal from the food source in o sanish. such as blowflies. In these organisms the dispersal of immatures includes two groups of in iduals, i ose that are actively migrating and those that have initiated the pupation process. The cassic ' diffusion equation in one dimension was modified to incorporate a function which describes the bury...g of larvae to become pupae. The analytical solution of this equation predicts oscillator an nonotonic dispersal behaviors, which are observed in experimental populations of blowfly species.

Key words: Chrysomya megacephala - Chrysomya putoria - C chlı nyia n acellaria - diffusion model - larval dispersal - blown 's

Diffusion models have been extensively er ployed to investigate dispersal and have yie ted considerable insight into the dynamics of anin. movement in space and time (Okubo 1980 eiva 1982, 1983, Andow et al. 1993, Chi tie 1 1995). Diffusion models can be written in simplest form as

$$
\frac{\mathbb{I} u}{\mathbb{I} t}=D \tilde{\mathrm{N}}^{2} u-f(u)
$$

where the operator $\tilde{\mathrm{N}}$ enote he spatial gradient, $t$ is time, $u(x, y, t)$ is the local pop llation density in the spatial variables $x$ an. 'v, $D$ s the coefficient of diffusion, and $f^{\prime} u$, the reaction term describing the net popul cion ch, ge due to birth and death. Whereas e a a a on (1) entails several simplifying assumptions abou the dispersal process (Andow et al. $y$. , the ease with which distinct behavioral tai $\ldots$ be incorporated has turned diffusion mo ls into a powerful tool (Holmes et al.

This work was supported by grants from FAPESP (No 94/3851-9, 94/5355-9, 95/8031-2, 95/9299-9).

${ }^{+}$Research Fellow CNPq

${ }^{++}$Corresponding author. E-mail: sergio@turing.unicamp.br Received 14 June 1996

Accepted 7 January 1997
1994, Equation (1) has been variously modified to take into account animal movement toward exte al stimuli or movement driven by wind or waer currents (Helland et al. 1984, Banks et al. 1988), correlation of movement between directions of travel (Holmes 1993), and cases where organisms have a tendency to move away from conspecifics (Gurney \& Nisbet 1975, see review in Holmes et al. 1994).

Most studies employing diffusion equations have described movement in adult animals (Andow et al. 1993), but this approach has seldom been used to study dispersal in immatures, whose dispersal has important consequences for the population and community dynamics and genetic structure of populations (de Jong 1979, Roughgarden et al. 1988, Gaines \& Bertness 1993). However, the same theoretical results concerning diffusion in adults can be applied to study dispersal in immatures (Broadbent \& Kendall 1953). In the present study a diffusion approach is employed to model the form of larval dispersal from the food source based on experimental data from three blowfly species, Chrysomya megacephala, C. putoria, and Cochliomyia macellaria. We take advantage of the flexibility of diffusion models to incorporate behavioral characteristics of dispersal in the larval stage. The model includes the classic diffusion and velocity terms and also a function which describes the process of larvae burying in the substrate to become pupae. The focus on these blowflies is 
motivated by the fact that the two Chrysomya species, which are native from the Old World and Australasia, are part of an ongoing invasion of the Americas (Guimarães et al. 1978, Baumgartner \& Greenberg 1984). The invading flies have dispersed rapidly throughout the continent and have apparently caused the decline in population numbers of the native species, C. macellaria (Guimarães et al. 1979, Guimarães 1984, Greenberg \& Szyska 1984).

\section{MATERIALS AND METHODS}

The process of larval migration from the food source was investigated in laboratory populations of C. megacephala, C. putoria and C. macellaria. Laboratory colonies were founded from specimens collected in the vicinities of the Universidade Estadual de Campinas, SP, Brasil, and these individuals were considered the parental generation. Adult flies were maintained at $25 \pm 1^{\circ} \mathrm{C}$ in cages $\left(30^{\prime} 30^{\prime} 48 \mathrm{~cm}\right)$ covered with nylon and were fed water and sugar ad libitum. Eggs were obtained by providing females with fresh beef liver. Newly hatched larvae, the $\mathrm{F}_{1}$ generation, were transferred to vials $(7.2 \mathrm{~cm}$ diameter, $13.8 \mathrm{~cm}$ height), containing $100 \mathrm{~g}$ of rearing media (Leal et al. 1982). Horizontal dispersal of full grown larvae was separately monitored for each species, depositing the vials at one end of a cardboard box $(3.0 \mathrm{~cm}$ long, $12 \mathrm{~cm}$ height, $30 \mathrm{~cm}$ wide), covered with wood shavings, $5 \mathrm{~cm}$ depth at the bottom. Dispers $\mathrm{A} \mathrm{W}_{\mathrm{c}}$ quantified (in $\mathrm{cm}$ ) as the distance travellea $\mathrm{v}^{\prime}{ }^{\prime}$. larvae from the starting point at one end of the $\mathrm{x}$ to the point where they buried to pupate. Two replicates were run, with the follow ig in mbers of larvae in each replicate: $C$. megac phala, 2 0, 294; C. putoria, 119, 214; C. macellar ?. 200, 24.

\section{RESU' IS}

Larval dispersal - Th process of larval dispersal of postfeeding larvat ${ }^{\circ} \mathrm{nm}$. ne food source in calliphorids suct as megacephala, C. putoria, and $C$. macella $a$ invol $\&$ individuals that are actually dispe sing vhile some of them begin to bury in the substrate pupate. Because of this character stic le form of dispersal can only be inferred wh ' $\mathrm{a}$ ' illum iduals have pupated. For each species, afto all individuals had pupated in the sub raw we counted the number of pupae observe at ach $20 \mathrm{~cm}$ interval from the release point at one nd of the cardboard box. Individual dispersal distances were then measured as the distance travelled by the postfeeding larvae from the point of release to the site of pupation.

The number of pupae found at each interval was plotted against distance travelled by the larvae and the overall pattern that emerges from this data set is similar for the three species in that they did not move far from the food source, and the number of larvae dispersing decreases with distance (Fig. 1). Nevertheless the two invading species differ remarkably from the native species in the shape of dispersal. In $C$. megacephala and $C$. putoria, the shape of dispersal shows a pattern of dampened oscillations, whereas in the nati - necies, C. macellaria, the number of dispe sing la vae apparently declines monotonically (. ig. 1).

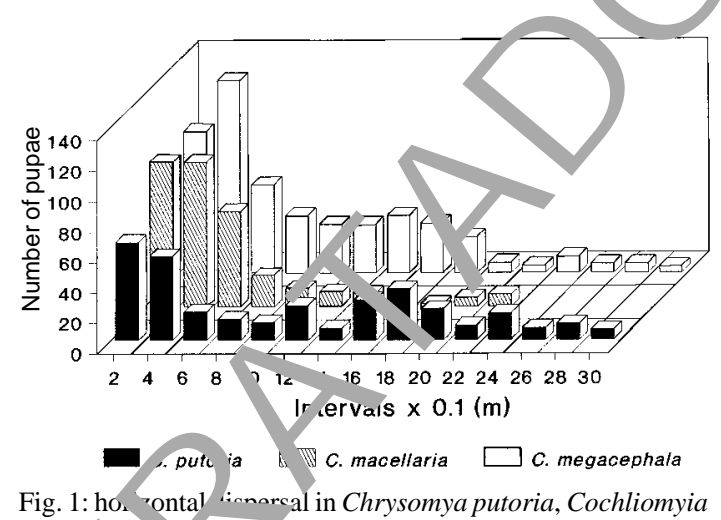
Fig. 1: ho, ont chrom
mace iria a. Chrysomya megacephala.

Diffu :on model - The diffusion model develor ad here takes into account both dispersing indi1dua $^{1}$ and those that have already buried, and is it en in one-dimensional space and time as:

$$
\frac{\mathbb{I} c(x, t)}{\mathbb{I} t}=D \frac{\mathbb{I}^{2} c(x, t)}{\mathbb{I} x^{2}}+\mathrm{a} \frac{\mathbb{I} c(x, t)}{\mathbb{I} x}-h(x, t),
$$

where $c(x, t)$ is the concentration of larvae on surface, $x$ is the one-dimensional spatial coordinate, $t$ is time, $D$ is the diffusion coefficient representing the random movement of the larvae and a is a coefficient of proportionality describing the velocity which is taken to be characteristic of each species. The first two terms in equation (2) describe the movement of larvae in the surface of the substrate. The last term in equation (2) is of particular importance in the context of larval migration because it is a function describing the rate of burying of the larvae.

As an approximation to the shape of spread of larvae shown in Fig. 1, the process of larval burying in the substrate is considered to decline exponentially with the distance dispersed by the larvae and to be directly proportional to the difference in concentration of the larvae. These assumptions then lead to

$$
\begin{aligned}
& h(x, t)=k\left[c_{0} \frac{\left(x^{*}-x\right)}{x^{*}} e^{-r x}-c(x, t)\right] \text { for } t £ t^{*} \text { and } \\
& x £ x^{*}
\end{aligned}
$$


where $k$ is a constant of proportionality, $c_{0}$ is proportional to the initial concentration of larvae, $x^{*}$ is the maximum distance travelled by the larvae, and $t^{*}$ indexes the end of dispersal when no larvae remain in the surface. Notice that $c(x, t)^{3} 0$ and $h(x, t){ }^{3} 0$ for $t £ t^{*}$. On the other hand, $t>t^{*}, c(x, t)$ $\circ h(x, t) \circ 0$.

The concentration of buried larvae at any point in time, $c^{*}(x, t)$, is given by

$$
c^{*}(x, t)=\int_{0}^{t} h(x, \tau) d \tau
$$

Using equation (3) in equation (4) we obtain

$$
c^{*}(x, t)=\frac{k c_{0}}{x^{*}}\left(x^{*}-x\right) t e^{-r x}-k \int_{0}^{t} c(x, \tau) d \tau \text { for } t
$$$$
£ t^{*} \text { and } x^{x} £ x^{*} \text {. }
$$

When $t>t^{*}$, there are no larvae left in the substrate. In this case,

$c^{*}\left(x, t^{*}\right)=\frac{k c_{0}}{x^{*}}\left(x^{*}-x\right) t^{*} e^{-r x}-k \int_{0}^{t^{*}} c(x, \tau) d \tau, x £ x^{*}$,

describes the end of the process of larval dispersal as a result of all larvae having buried in the substrate, which implies

$$
\frac{\partial c\left(x, t^{*}\right)}{\partial t}=0 .
$$

From equations (2) and (7),

$$
D \frac{\partial^{2} c}{\partial x^{2}}+\alpha \frac{\partial c}{\partial x}-h(x, t)=0,+, t=t^{*}
$$

Since the derivatives in er atio ( $)$ ) $d$ not depend on time we have

$$
\frac{d^{2} c}{d x^{2}}+\frac{\alpha}{D} \frac{d c}{x}+\frac{k}{D} c=\frac{0}{D x^{*}}\left(x^{*}-x\right) e^{-r x} .
$$

The solution $\mathrm{a}$, the homogeneous part of equation $(0,1 \mathrm{~s} f$ the form

$$
c_{h}(x)=A e^{\lambda_{1} x}+B e^{\lambda_{2} x},
$$

ai $t^{1} e$ roots $\left(I_{i}\right)$ are given by the characteristic equ tion

$$
\lambda_{i}=\frac{-p \pm \sqrt{p^{2}-4 q}}{2}, i=1,2,
$$

where $p=a / D$ and $q=k / D$. The real parts of $l_{1}$ and $l_{2}$ are always negative, yielding solutions with exponential decay. The case $p^{2} £ 4 q$ is relevant for the understanding of the pattern of dispersal be- cause the associated complex roots $l_{1}$ and $l_{2}$ describe the damped oscillations observed in our experiments of larval dispersal (Fig. 1). The discriminant in the characteristic equation establishes a relationship between the coefficients of diffusion, $D$, the velocity of dispersal, a, and the constant of proportionality $k$, as follows.

If $p^{2} £ 4 q$ we have that

$$
\frac{\alpha^{2}}{D}<4 k
$$

For the case where inequality (I holds the homogeneous solution to equa $a^{\circ}$ (9) can ${ }^{b}-$ written as

$$
c_{h}(x)=\beta \cos (a \times-\theta) e^{-\frac{p}{2} x},
$$

with $\omega=\sqrt{4 q-} / \overline{p^{2}} / 2$

\section{A partict ar so ation to (9) can be found as}

$$
c_{p}(x)=\left(B_{1}+A_{1} x\right) e^{-r x} .
$$

ubstitu $\operatorname{ng} c_{p}(x)$ in equation (9) we obtain

and

$$
A_{1}=\frac{-q c_{0}}{x^{*}\left(r^{2}-r p+q\right)}
$$

$$
B_{1}=\frac{q c_{0}\left[p-2 r+x^{*}\left(r^{2}-p r+q\right)\right]}{x^{*}\left(r^{2}-p r+q\right)^{2}} .
$$

The general solution to equation (8) is thus found as

$$
c(x)=\beta \cos (\omega x-\theta) e^{-\frac{p}{2} x}+\left(B_{1}+A_{1} x\right) e^{-r x}
$$

Finally, using equation (13) in equation (6) we arrive at an expression for the distribution of larvae at equilibrium, that is, when all larvae have buried to pupariate and dispersal in the substrate has ended,

$$
c^{*}\left(x, t^{*}\right)=-\beta t^{*} \cos (\omega x-\theta) e^{-\frac{p}{2} x}+k t^{*}\left[c_{0}-B-\left(A_{1}+\frac{c_{0}}{x^{*}}\right) x\right] e^{-x} .
$$

\section{DISCUSSION}

Insects whose immature stages migrate from the food source in search of pupation sites, characterize a particular system with two populations; one of actively migrating larvae and the other of larvae burying to pupate. The process of larval dispersal is completed when all larvae have buried and no larvae remain dispersing in the substrate. These fundamental aspects were taken into account in our model by adding to the diffusion equation a 
function, $h(x, t)$, describing the process of larval burying in the substrate. This function involves biologically important parameters such as the initial concentration of larvae, the maximum distance travelled by the larvae during dispersal and the time taken for dispersal to occur. The form of this function was inferred from the experimental data presented here that suggests that the decrease of the number of pupae with distance from the source is exponential.

The diffusion equation incorporating the burying function yielded an analytical solution (equation 14), which describes the equilibrium distribution of larvae buried in the substrate. This analytical solution was used to compare the dispersal behavior predicted by the diffusion model with the observed data for C. megacephala, C. putoria, and C. macellaria. Equation 14 was fitted to the data using a nonlinear regression whose details are described in the Appendix. Fig. 2 shows the fit of equation 14 to the dispersal data for the three species and demonstrates that the equilibrium distribution given by the diffusion model is consistent with the observed pattern of larval dispersal in the blowflies analyzed here. In other words, the diffusion equation incorporating the burying function seems to account for both the oscillatory and mono. tonic decrease in the number of pupae with increasing distance from the food source. The compl ${ }^{1}$ t $v$ in behavior of dispersal as indicated by the $\mathrm{i}$ equa ity in (10) is apparently the outcome of an in 4 . ction between the velocity $\left(\mathrm{a}^{2}\right)$, the random mov ment of larvae in these blowflies in - ved by the diffusion coefficient $(D)$, and a so inve ves the constant of proportionality $(k) \mathrm{g}$ verning he rate at which larvae bury in the stra.

Diffusion models hav been tensively used to address ecological pi blems ( )kubo 1980, Murray 1989, Holmes et a. ' 994 and have been particularly useful $\mathrm{O} \mathrm{a}$. sects (Kareiva 1' 83, Anc w et al. 1993). Nevertheless this ar roa $h$ apparently has not been explored to understand $\mathrm{t}$ dispersal behavior of immature in ects uch as blowflies, where two groups of indivia als ater.m. racting, those that are actively migrating an those that have already buried in the sub. raw The present effort is a first approximation $t^{\prime}$ ' complex problem of larval dispersal, which 1 cludes factors acting at the individual level such as ine minimum weight necessary for pupation (Ullyett 1950) and those intervening at the population and community levels including the timing and the velocity with which larvae leave the substrate (Peschke et al. 1987, Blackith \& Blackith 1990), the spatio-temporal patterning of predation and parasitism (Norris 1959, Putman 1977, Peschke

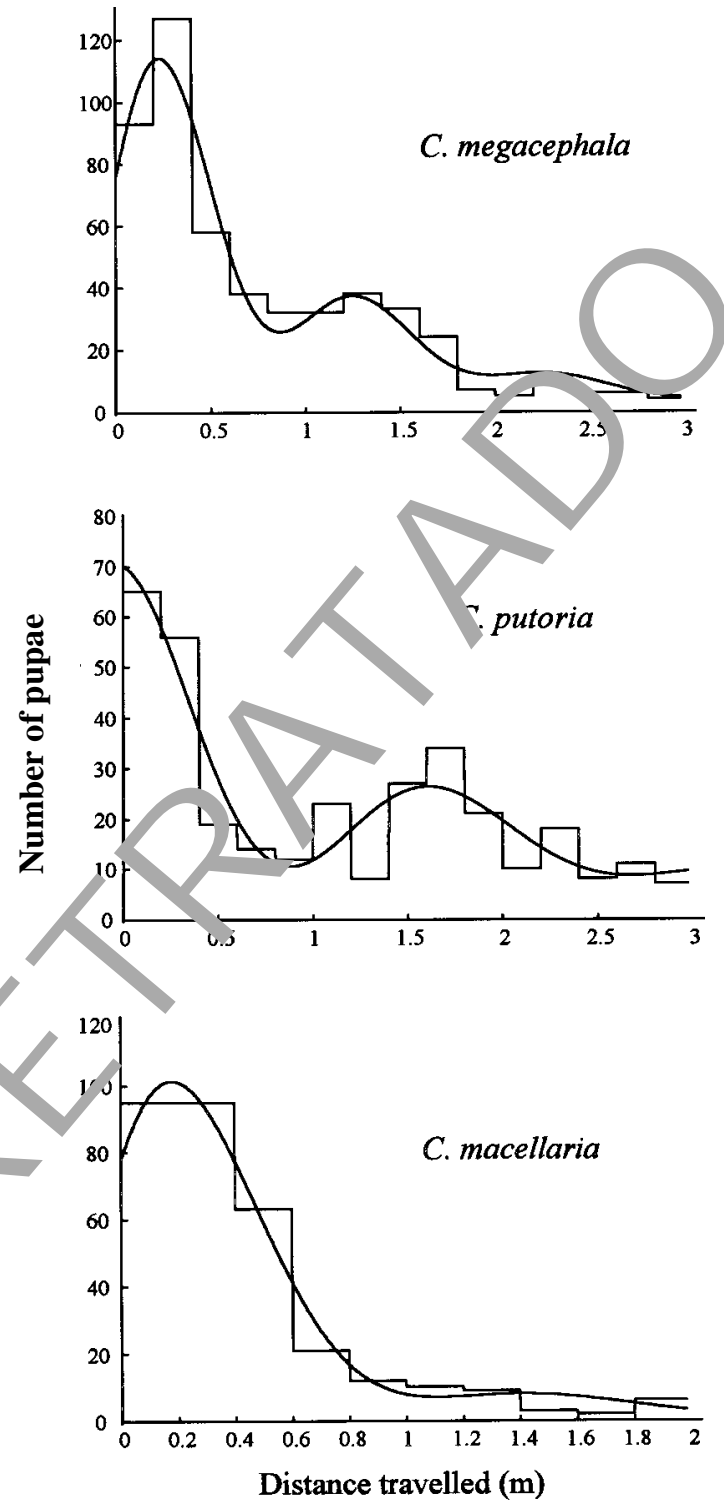

Fig. 2: fit of the diffusion model to dispersal data for Chrysomya megacephala, Chrysomya putoria, and Cochliomyia macellaria. The histograms are based on number of pupae plotted against distance travelled in meters and the curve fitted to the data is based on the solution of the diffusion equation (equation 14)

et al. 1987, Sereno \& Neves 1993), the physical makeup of the substrate, and the availability of suitable places to pupate (Kneidel 1984).

The application of diffusion theory has a rich tradition of illuminating mechanisms and processes in population biology (Kareiva 1983), and we believe that the approach presented here follows this tradition. As in other studies (e.g. Kareiva 1983, 
Possingham \& Roughgarden 1990), simplifying assumptions were made such as the invariance of diffusion coefficients with space, time, and larval density. Nevertheless, the primary purpose of the model presented here was to develop a framework to analyze dispersal of immature insects living in carrion or other ephemeral substrates. The simple passive diffusion model approach taken here does include two relevant features in that it explicitly accounts for the dispersing life-stage and assumes that the dispersal distances are limited, which is commonly regarded as a limitation in diffusion models such as those applied to the dispersal of adult insects (Andow et al. 1993). We believe that the model presented here may prove a useful tool to explore the diffusion dispersal dynamics of organisms such as blowflies and other diptera where the same phase of the dispersing cycle in immatures has two stages, i.e., one actively moving and the other burying in the substrate.

\section{ACKNOWLEDGMENTS}

To two anonymous reviewers for comments that helped to improve the clarity of the manuscript.

\section{REFERENCES}

Andow DA, Kareiva PM, Levin SA, Okubo A 1993 Spread of invading organisms: patterns of disper al, p. 219-242. In KC Kim, BA McPheron (eds), lution of insect pests. John Wiley, New York.

Banks HT, Kareiva PM, Zia L 1988. Anal All field studies of insect dispersal using two- men 1 transport equations. Environ Ent 17: 815-

Baumgartner DL, Greenberg B 1984. The genus ryysomya (Diptera: Calliphoridae) in the New World. $J$ Med Ent 21: 105-113.

Blackith RE, Blackith RM 1990 Insect in estations of small corpses. J Nat Hist 24: 99-709

Broadbent SR, Kendall D' 1953. 'T w. undom walk of Trichostrongylus $r$ ortat o nis. Biometrika 9: 460-465.

Christie I, Wilder JV, Colb - II 95 . Modeling of onedimensional pa. 1 effects on the spread of gypsy moths. Ecr Model, o. 219-234.

de Jong $G 1$, The influence of the distribution of juveniles over ${ }_{\mathrm{P}}{ }^{+}$ches of food on the dynamics of a por a. on. Nethe, J Zool 29: 33-51.

Gain SD, sortness M 1994. The dynamics of juvenile disp " al: why field ecologists must integrate. Ecology 74. $430-2435$.

( reen. - B, Szyska ML 1984. Immature stages and bi logy of fifteen species of Peruvian Calliphoridae Oiptera). Ann Ent Soc Amer 77: 488-517.

Guim , arães JH 1984. Considerações gerais sobre moscas do gênero Chrysomya no Brasil. Agroquímica 24: 8-12.

Guimarães JH, Prado AP, Linhares AX 1978. Three newly introduced blowfly species in Southern Brazil (Diptera: Calliphoridae). Revta bras Ent 22: 53-60.

Guimarães JH, Prado AP, Buralli GM 1979. Dispersal and distribution of three newly introduced species of Chrysomya Robineau-Desvoidy in Brazil (Diptera: Calliphoridae). Revta bras Ent 23: 245255.

Gurney WSC, Nisbet RM 1975. The regulation of inhomogeneous populations. J theor Biol 52: 441-457.

Helland IS, Hoff JM, Anderbrant G 1984. Attraction of bark beetles (Coleoptera: Scotylidae) to a pheromone trap: experiment and mathematical mo $1 \mathrm{~s}$. Chem Ecol 10: 723-752.

Holmes EE 1993. Are diffusion models o simple A comparison with telegraph modelc of $1_{\mathrm{t}}$ acion. Am Nat 142: 403-419.

Holmes EE, Lewis MA, Banks J_ Veit RR 994. Partial differential equations in ecology spatia interactions and population dynami Fcology. 5 17-29.

Ives AR 1991. Aggregation nd cr ince in a carrion fly community. E sl Mo, 6: 75-94.

Kareiva PM 1982. F erimenta nd mathematical analyses of herbiv e $m_{1}$ ement: Quantifying the influence of plant spacing $\eta$ foraging discrimination. Ecol Mo, of 52: 261-282.

Kareiva PM 1 83. , movement in herbivorous insects: apply a passive diffusion model to markre aps. e fielc experiments. Oecologia 57: 322-327.

Kne. $\mathrm{l} \mathrm{K} . \mathrm{1}$ Competition and disturbance in commu. es of carrion-breeding Diptera. J Anim Ecol 53: 84,965 .

Lc. TT, Prado AP, Antunes AJ 1982. Rearing the larVa of blowfly Chrysomya chloropyga (Wiedemann) (Diptera, Calliphoridae) on oligidic diets. Rev bras Zool 1: 41-44.

Murray JD 1989. Mathematical biology. SpringerVerlag, Berlin, 787 pp.

Norris KR 1959. The ecology of sheep blowflies in Australia, p. 514-544. In A Keast, RL Crocker, CS Christian (eds), Biogeography and ecology in Australia. Volume 8. Junk, The Hague.

Okubo A 1980. Diffusion and ecological problems: Mathematical models. Springer-Verlag, New York, $245 \mathrm{pp}$.

Peschke K, Krapp D, Fuldner D 1987. Ecological separation, functional relationships, and limiting resources in a carrion insect community. Zool Jahr Syst 114: 241-265.

Possingham HP, Roughgarden J 1990. Spatial population dynamics of a marine organism with a complex life cycle. Ecology 71: 973-985.

Prout T, McChesney F 1985. Competition among immatures affects their adult fertility: population dynamics. Am Nat 126: 521-558.

Putman RJ 1977. Dynamics of the blowfly, Calliphora erythrocephala, within carrion. J Anim Ecol 46: 853866.

Roughgarden J, Gaines SD, Possingham HP 1988. Recruitment dynamics in complex life cycles. Science 241: 1460-1466.

Sereno FTPS, Neves DP 1993. Ocorrência natural de microhimenópteros parasitóides de pupas de moscas em aviário. An Soc Ent Bras 22: 527-533.

Ullyett GC 1950. Competition for food and allied phenomena in sheep-blowfly populations. Phil Trans $R$ Soc London B234: 77-174. 


\section{Appendix}

Nonlinear Parametric Regression to Estimate the Parameters of Equation (14)

The parameters presented in equation (14) can be grouped and renamed to produce the following nonlinear regression model:

$$
c^{*}\left(x, t^{*}\right)=a_{1} \cos \left(a_{2} x-a_{3}\right) e^{-a_{4} x}+\left(a_{5}+a_{6} x\right) e^{-a_{7} x} .
$$

For the three species C. megacephala, C. putoria and $C$. macellaria, the objective is to determine the corresponding set of parameters $\left\{a_{1}, \ldots, a_{7}\right\}$ from the experimental data $\left(x_{i}, y_{i}\right), i=1, \ldots, N$. Here, $x$ (the explanatory variable) denotes the distance travelled, $y$ (the response variable) denotes the corresponding number of buried larvae, and $N$ is the number of discrete distances considered (Fig. 1).

The set of parameters $\left\{a_{1}, \ldots, a_{7}\right\}$ can be estimated through nonlinear parametric regression, generally described as the minimization of the mean square error:

$$
\min _{a_{1}, \ldots, a_{7}} \frac{1}{2} \sum_{i=1}^{N}\left(c^{*}\left(x_{i}, t^{*}\right)-y_{i}\right)^{2}=\min _{a_{1}, \ldots, a_{7}} J\left(a_{1}, \ldots, a_{7}\right) .
$$

Denoting the gradient of $J(\cdot)$, the vector of first $\nabla J\left(a_{1}, \ldots, a_{7}\right)=\left[\begin{array}{c}\frac{\partial j}{\partial a_{1}} \\ \vdots \\ \frac{\partial J}{\partial a_{7}}\end{array}\right]=\sum_{i=1}^{N}\left(c^{*}\left(x_{i}, t^{*}\right)-y_{i}\right)\left[\begin{array}{c}\frac{\partial c^{*}\left(x_{i}, t^{*}\right)}{\partial a_{1}} \\ \frac{\partial c^{*}\left(a_{1}\right.}{\partial a_{7}} t^{*}\end{array}\right)$,

where

$$
\begin{aligned}
& \frac{\partial c^{*}\left(x, t^{*}\right)}{\partial a_{1}}=\cos \left(a_{2} x-a_{3}\right)-a_{4} x \\
& \left.\frac{\partial c^{*}\left(x, t^{*}\right)}{\partial a_{2}}=x a_{1} s_{1}-a_{3}\right) e^{-a_{4} x} \\
& \frac{\partial c^{*}\left(x, t^{*}\right)}{\partial}=a_{1} \operatorname{in}\left(a_{2} x-a_{3}\right) e^{-a_{4} x}
\end{aligned}
$$

$$
\begin{aligned}
& \frac{\partial c^{*}\left(x, t^{*}\right)}{\partial a_{4}}=-x a_{1} \cos \left(a_{2} x-a_{3}\right) e^{-a_{4} x} \\
& \frac{\partial c^{*}\left(x, t^{*}\right)}{\partial a_{5}}=e^{-a_{7} x} \quad \frac{\partial c^{*}\left(x, t^{*}\right)}{\partial a_{6}}=x e^{-a_{7} x} \\
& \frac{\partial c^{*}\left(x, t^{*}\right)}{\partial a_{7}}=-x\left(a_{5}+a_{6} x\right) e^{-a_{7} x}
\end{aligned}
$$

We are now prepared to estir. te the se of parameters $\left\{a_{1}, \ldots, a_{7}\right\}$ that minimizes $(\cdot) b /$ means of the following iterative $a l_{2}$ on

Initialization: Set ran om init , values to $\left\{a_{1}, \ldots\right.$, $\left.a_{7}\right\}$ and an arbitrary on. "1 value o e;

Step 1: compr $-\frac{\partial J}{\partial u}, i=1, \ldots, 7$;

Step 2: find a po ave value to $s$ such that the new val eso $\left\{a_{1}, \ldots, a_{7}\right\}$ given by

$$
a_{i}^{n_{\mathrm{c}}}=a_{i}^{\text {old }}-\sigma \frac{\partial J}{\partial a_{i}}, i=1, \ldots, 7,
$$

produce $Y\left(a_{1}^{\text {new }}, \ldots, a_{7}^{\text {new }}\right)<J\left(a_{1}^{\text {old }}, \ldots, a_{7}^{\text {old }}\right)$;

step? if $J\left(a_{1}, \ldots, a_{7}\right)>\varepsilon$, return to step 1 .

Given the experimental data, the application of this algorithm for each species gives:

C. megacephala: $a_{1}=60.0872 ; a_{2}=5.9472 ; a_{3}=$ $1.8544 ; a_{4}=1.4474 ; a_{5}=$ 93.2371; $a_{6}=26.6265 ; a_{7}=$ 1.1573

C. putoria: $a_{1}=34.8800 ; a_{2}=3.6839 ; a_{3}=0.1634$;

$$
a_{4}=0.9026 ; \quad a_{5}=35.7570 ;
$$$$
a_{6}=13.9524 ; a_{7}=0.6872
$$

C. macellaria: $a_{1}=85.6961 ; a_{2}=4.6069 ; a_{3}=$ $1.6826 ; a_{4}=2.3604 ; a_{5}=87.6527$; $a_{6}=17.6138 ; a_{7}=1.9009$ 